\title{
Impact of olive mill wastewater (OMW) on the soil hydraulic and solute transport properties
}

\author{
A. Comegna ${ }^{1}$ [D $\cdot$ G. Dragonetti ${ }^{2} \cdot$ R. Kodesova ${ }^{3} \cdot$ A. Coppola ${ }^{1}$
}

Received: 21 April 2021 / Revised: 20 July 2021 / Accepted: 21 August 2021 / Published online: 1 September 2021

(c) The Author(s) 2021

\begin{abstract}
The Mediterranean area concentrates the world's largest production area of olive oil. The olive oil industry represents, in this basin, one of the leading sectors of the agri-food economy. Olive mill water (OMW) is the principal waste effluent produced by the olive oil industry. Due to its high pollution load, this aqueous by-product cannot be directly disposed of in domestic wastewater treatment plants (especially those with a biological treatment unit). Untreated OMW is currently used for agronomic purposes in several countries, mainly because it is rich in valuable plant nutrients. However, OMW is characterized by toxic phenols, high organic matter, high salinity, suspended solids and several other components that may have possible negative effects on chemical and physical soil properties, as well as soil biological activities. In the present research, we focused on the effects of OMW application on transport and hydraulic soil properties. Three distinct soils from a pedological point of view were selected and a series of laboratory steady-state miscible flow tests were conducted under saturated conditions, on both OMW-treated and -untreated soil columns. Tests were conducted on disturbed and undisturbed soil columns. The approach proposed by Kachanoski, based on soil impedance $(Z)$ measurements via the time domain reflectometry (TDR) technique, was used to monitor the leaching experiments. The breakthrough curves (BTCs) exhibited different shapes that allowed the repercussions of OMW applications on soil transport behaviour to be distinguished. Several additional tests conducted on OMW-treated and -untreated soil cores to determine water retention curves (SWRCs) and saturated hydraulic conductivity $K_{s}$ allowed us to infer the probable mechanisms involved in soil hydrological behaviour changes under OMW treatments. The results show that when OMW leaches into the soil immediately after its disposal there is little effect on the evaluated hydraulic and hydrodispersive properties. By contrast, we demonstrated that a short incubation period (i.e. a short contact time between OMW and soil) of 10 days is enough to exert a great influence on all the values determined (e.g. soil pore velocity $v$ and $K_{s}$ reduced by up to one order of magnitude). These effects were especially evident in undisturbed soil samples.
\end{abstract}

Editorial responsibility: Maryam Shabani.

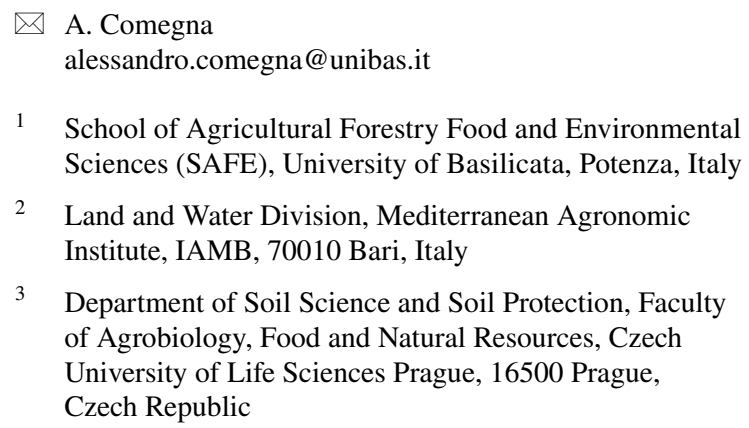

1 School of Agricultural Forestry Food and Environmental Sciences (SAFE), University of Basilicata, Potenza, Italy

2 Land and Water Division, Mediterranean Agronomic Institute, IAMB, 70010 Bari, Italy

3 Department of Soil Science and Soil Protection, Faculty of Agrobiology, Food and Natural Resources, Czech University of Life Sciences Prague, 16500 Prague, Czech Republic 


\section{Graphic Abstract}

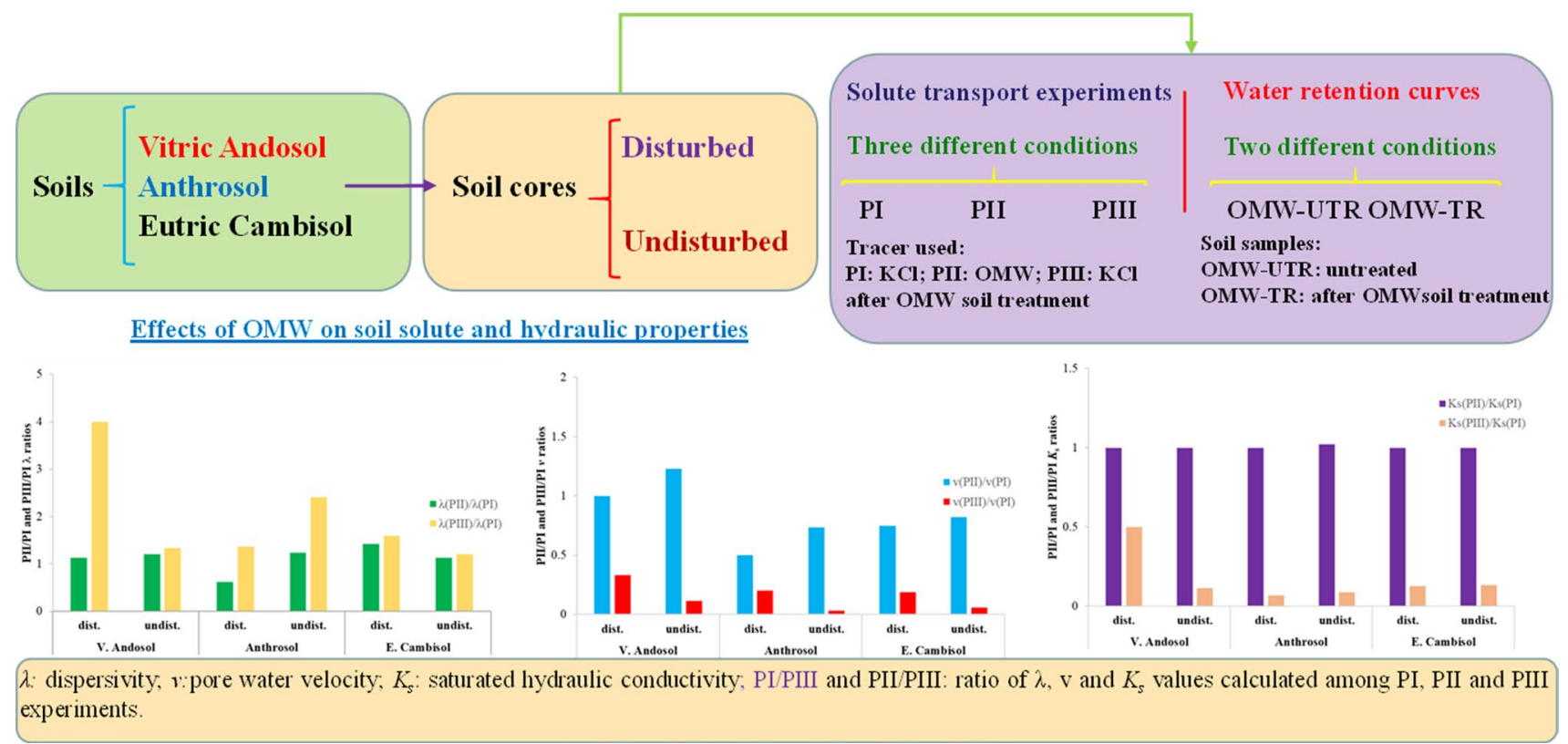

Keywords Hydraulic conductivity $\cdot$ Hydraulic properties of soils $\cdot$ Olive mill wastewater $\cdot$ Retention curves $\cdot$ Solute transport $\cdot$ Soil transport parameters $\cdot$ TDR technique

\section{Introduction}

OMW is a primary waste product of olive oil processing. In several countries where olive oil production is very intensive, OMW is often recycled as a low-cost fertilizer, since OMW is naturally rich in mineral elements (Kavvadias et al. 2014; Mohawesh et al. 2014; Chatzistathis and Koutsos, 2017; Mekki et al., 2018; Chehab et al., 2019).

The practice of spreading OMW on agricultural lands is a controversial question, mostly because the reported effects of OMW on physico-chemical and biological soil properties are often apparently contrasting. Different outcomes are conceivably due to the intrinsically complex (i.e. multiphase) nature of both OMWs and soils, which in turn produces multifactorial physico-chemical interactions among all the distinct phases involved in the OMW soil domain (Saadi et al. 2007; Lopez-Piniero et al. 2008; Pedrero et al. 2020).

However, recent studies clearly established that OMW (especially at high rates and for recurrent land application) has toxic consequences on plants, soils and groundwaters. These effects may last in soils for years because OMW constituents are usually affected by low degradable rates and thus represent a potential long-term source of soil pollution (Mahmoud et al. 2010; Piotrowska et al. 2011; Caputo et al. 2013; Kavvadias et al. 2014; Umeugochukwu 2016; Meftah et al., 2019).
From a hydrological standpoint, several studies have shown that high concentrations of suspended solids, organic matter, potassium (K) and sodium $(\mathrm{Na})$ in OMW have the potential to reduce the saturated soil hydraulic conductivity (Mohawesh et al. 2014; Regni et al., 2017). Furthermore, lipidic constituents (i.e. oil and fats) may increase the degree of soil repellence, especially in the topsoil horizons (Mahmoud et al. 2010), modifying water and solute infiltration rates (Belaqziz et al., 2008, 2016; Barbera et al. 2013; Magdich et al., 2016). In general, all the above substances would alter the original porosity of soils, with the result of reducing the radius of larger pores, thereby increasing the percentage of smaller pores (Cox 1997; Mohawesh et al. 2014; Sahraoui et al. 2015). Albalasmeh et al. (2019) also documented the short-term impact of OMW, which may favour growth in aggregate stability but also increase soil penetration resistance, besides leading to a decrease in hydraulic conductivity. Levy et al. (2018) also showed a positive impact of OMW on soil aggregate stability, although they found no evident influence on the hydraulic conductivity of a sandy-loam soil. Steinmetz et al. (2015) did not show any influence on hydraulic conductivity, but found an increase in water repellence. Mahmoud et al. (2012) documented that long-term treatment with OMW (conditions similar to those of Mahmoud et al. 2010) leads to greater aggregate stability and lower transport of water and solutes into aggregates, which may result in the risk of possible 
enhanced preferential solute transport following greater fragmentation of soil aggregates.

In structured soils, Jarvis et al. (2008) observed that soil repellence may stimulate non-equilibrium water and solute transport mechanisms. Non-native large deep cracks favouring preferential flow dynamics were observed by Gharaibeh et al. (2007) in an OMW field experiment lasting 15 years. In all these cases, OMW applications appeared to increase the vulnerability of groundwater, becoming more susceptible to contaminants (Roig et al. 2006; Andreozzi et al. 2007).

Furthermore, Steinmetz et al. (2015) documented that the impact of OMW on soil properties may also depend on the season of application (e.g. different degradation and leaching of OMW compounds under different temperature, precipitation, etc.). The degree of soil property alteration can also depend on the stage of soil consolidation (i.e. development of soil structure due to periodical agricultural processing, see for example Jirku et al. 2013 and Nikodem et al. 2021).

However, clear results explaining OMW alterations of soil properties and the mechanisms involved are still lacking.

The purpose of this study was to test two hypotheses. First, it can be assumed that the hydraulic and transport properties of disturbed soils are less affected than those of consolidated soils. In consolidated soils, constituents already form structural elements (i.e. pores in these soils are hierarchically arranged, that is, fine pores inside aggregates and larger pores between aggregates) and OMW compounds can be mainly accumulated in the larger pores forming a coating on aggregates and so forth, which can consequently greatly affect pore size distribution and even pore connectivity. By contrast, completely disturbed soils have a simple pore arrangement, and thus, OMW compounds can be equally distributed in all pores. Hence, the changes in pore sizes and pore connectivity may be less pronounced. Therefore, this study focused on the evaluation of OMW influence on transport and hydraulic properties of soils in two different stages of consolidation, i.e. disturbed soil samples, representing the soil after its thorough processing, and undisturbed soil samples, representing well-consolidated soil. The second hypothesis was that new structural features, i.e. complexes between the original soil constituents and OMW compounds, are not formed during and immediately after OMW irrigation, and thus, OMW compounds can be leached by subsequent rainfall. Therefore, the immediate and 10-day incubation-induced effect of OMW on soil hydraulic and transport processes was investigated.

To elucidate some of the effects of OMW on soil hydraulic and transport processes of three different soils, we performed a series of laboratory steady-state solute transport experiments on soil columns untreated and treated with OMW. Potassium chloride $(\mathrm{KCl})$ was assumed as a transport tracer. During these tests, following the consolidated approach proposed by Kachanoski et al. (1992) and widely adopted in the literature (Comegna et al. 1999; Coppola et al. 2009a, among others), changes in TDR signal attenuation were successfully used for monitoring solute concentration evolution in soil columns. The saturated hydraulic conductivities were also measured on the same columns, while the soil water retention curves (SWRC) were determined using independently treated soil samples.

\section{Materials and methods}

\section{Transport model linked to TDR measurements}

The time domain reflectometry (TDR) technique, in soil physics, is a well-known geophysical method that permits simultaneous estimation of the bulk dielectric permittivity $\varepsilon_{b}$ (Topp et al. 1980) and the bulk electrical conductivity $E C_{b}$ (Dalton et al. 1984) of soils. Numerous researchers (Butters and Jury 1989; Radcliffe et al. 1998; Mallants et al. 1994; Persson and Berndtsson 2002; Severino et al. 2010; Francisca and Montoro 2012; Dragonetti et al. 2018; Comegna et al. 2013a, 2013b, 2013c, 2016, 2017, 2019, 2020 among others) have demonstrated the high accuracy of the TDR technique for soil contaminant characterization.

Kachanoski et al. (1992), exploiting these potentials, built a TDR-based methodology to usefully characterize contaminant movement in soils. Briefly, Kachanoski's approach mainly relies on the so-called late time impedance (LTI) method of Nadler et al. (1991), which coupled $E C_{b}$ to the TDR-measured impedance $Z$, and the latter to the mass of a solute tracer added to the soil. Rhoades et al. (1976 and 1989) demonstrated that, under steady-state flow conditions (at constant soil volumetric water content $\theta$ ), $E C_{b}$ linearly depends on the soil solution electrical conductivity $E C_{w}$, which in turn linearly relies on the free salt in the liquidfilled pores (i.e. on the mass of an electrolyte in the soil aqueous solution).

Given the above assumptions, Kachanoski et al. (1992) showed that in a medium in which a TDR probe of length $L$ is vertically installed, the impedance of the TDR-reflected signal is inversely correlated with the mass of the tracer surrounding the TDR rods. This dependence can be written as follows:

$M_{r, L}(t)=\frac{Z_{L}^{-1}-Z_{i}^{-1}}{Z_{0}^{-1}-Z_{i}^{-1}}$

where $M_{r, L}(-)$ is the relative solute mass situated above the reference depth $L(\mathrm{~cm})$ (since in our experiments the reference depth $L$ is equal to the soil height, $M_{r, L}$ has to be considered as the solute mass within the soil sample), $Z_{L}(\Omega)$ is the impedance load measured at time $t(\mathrm{~min})$ during the transport experiment, $Z_{i}(\Omega)$ is the background impedance 
(i.e. the impedance before the solute was spread to the soil) and $Z_{0}(\Omega)$ is the impedance measurable in the soil when the solute is moving within it, but before the tracer passed the bottom of the sample at depth $L$.

Equation (1), for the case of a pulse input of solute of initial mass $M_{0}$ added from the surface, allows us to build the solute breakthrough curve (BTC) directly from TDR measurements of $Z$.

Following the assumptions of Jury and Roth (1990), solute transport parameters, that is i) soil pore water velocity $v(\mathrm{~cm} / \mathrm{min})$, and ii) dispersivity $\lambda(\mathrm{cm})$, can be estimated by adopting a nonlinear least-square optimization procedure that fits the experimental BTCs to the convection-dispersion equation (CDE). The analytical CDE solution, for the relative specific mass of solute remaining within depth $L$, is yielded by Elrick et al. (1992):

$M_{r, L}(t)=1-\left[\frac{1}{2} \operatorname{erfc}\left(\frac{L-v t}{2 \sqrt{\lambda v t}}\right)+\frac{1}{2} \exp \left(\frac{v L}{\lambda v}\right) \operatorname{erfc}\left(\frac{L+v t}{2 \sqrt{\lambda v t}}\right)\right]$

where $\operatorname{erfc}$ is the complementary error function.

\section{Soil and OMW physico-chemical characterization}

In the present research, experiments were carried out using soil samples of different structures and textures, collected from the Ap horizon of three soil sites in southern Italy. Table 1 reports the main physico-chemical features of the selected soils (Vitric Andosol, Anthrosol, Eutric Cambisol) with a focus on the soil pedological classification, according to the IUSS Working Group WRB (2006). Soil texture, organic content $(O C), p H$ and soil bulk density $\left(\rho_{b}\right)$ were determined using, respectively, the methods proposed by Day (1965), Allison (1965), Eckert (1988), and Blake and Hartge (1986).

OMW used in the present research was stored at a controlled temperature of $4{ }^{\circ} \mathrm{C}$ in order to keep the wastewater stabilized over time. Some of the main properties of OMW are reported in Table 2. The $p H$ was measured with a Cyberscan pH metre (model 2500), while a conductivity metre (Cyberscan model 500) was used to obtain the electrical conductivity $\left(E C_{O M W}\right)$. The dissolved oxygen concentration $(D O)$ and the total dissolved solids (TDS) were measured
Table 2 Selected physico-chemical properties of the OMW used in the laboratory experiments

\begin{tabular}{ll}
\hline Parameter & Value \\
\hline$p H$ & 3.85 \\
$\mathrm{EC}_{\mathrm{OMw}}$ at $20{ }^{\circ} \mathrm{C}(\mathrm{dS} / \mathrm{m})$ & 10.20 \\
$\mathrm{DO}(\mathrm{mg} / \mathrm{l})$ & 0.23 \\
$\mathrm{TDS}(\mathrm{mg} / \mathrm{l})$ & 6016 \\
$\mathrm{TN}(\mathrm{mg} / \mathrm{l})$ & 650 \\
$\mathrm{COD}(\mathrm{mg} / \mathrm{l})$ & 110,000 \\
Polyphenols $(\mathrm{mg} / \mathrm{l})$ & 10,400 \\
\hline
\end{tabular}

with a multiparametric probe (Hanna Instruments, model HI9829). The Kjeldahl method (Helrich 1990) was used for the total nitrogen $(T N)$ concentration. Total phenolic content was estimated with the colorimetric method, based on the Folin-Ciocalteu reagent (Box, 1983). Finally, chemical oxygen demand $(C O D)$ was determined using the IRSA-CNR \#5130 method (IRSA-CNR, 2003), which is a laboratory analysis based on the oxidation of inorganic and organic substances present in a water sample, using a $0.25 \mathrm{~N}$ solution of potassium dichromate.

\section{Transport experiments}

Solute transport tests were performed in the laboratory on disturbed (i.e. repacked) and undisturbed (i.e. non-repacked) soil cores $80 \mathrm{~mm}$ in diameter and $110 \mathrm{~mm}$ in length. The undisturbed columns were collected using PVC samplers driven by a hydraulic device, ensuring the simultaneous removal of the surrounding material, to minimize any density alteration of the samples. For the disturbed columns, the soil was sieved at $2 \mathrm{~mm}$, mechanically homogenized and then placed, in several steps, in PVC containers until the on-site bulk density, $\rho_{b}$, was obtained. The bottom end of the soil column was held with a nylon gauze $(25 \mu \mathrm{m})$. The entire soil set (i.e. disturbed and undisturbed soil columns) consisted of six columns (two for each soil).

A diagram of the laboratory apparatus is shown schematically in Fig. 1. The equipment included: i) a rainfall simulator connected to a peristaltic pump for solute application, ii) a Mariotte vessel system for water application, iii) a Tektronix (model 1502C) cable tester connected to a TDR probe, with
Table 1 Principal physicochemical properties and pedological classification of the soils investigated

\begin{tabular}{llllllll}
\hline $\begin{array}{l}\text { Soil pedological } \\
\text { classification* }\end{array}$ & \multicolumn{2}{l}{ Soil texture and classification (USDA) } & & $\begin{array}{l}\rho_{b} \\
\left(\mathrm{~g} / \mathrm{cm}^{3}\right)\end{array}$ & $\begin{array}{l}\text { OC } \\
(\%)\end{array}$ & $p H$ \\
\cline { 2 - 5 } & Texture & Sand (\%) & $\begin{array}{l}\text { Clay } \\
(\%)\end{array}$ & $\begin{array}{l}\text { Silt } \\
(\%)\end{array}$ & & & \\
\hline Vitric Andosol & Sand & 80.0 & 8.0 & 12.0 & 1.16 & 1.90 & 7.30 \\
Anthrosol & Silt Loam & 15.7 & 11.6 & 72.7 & 1.13 & 1.84 & 8.37 \\
Eutric Cambisol & Loam & 41.4 & 16.4 & 42.2 & 1.27 & 0.30 & 8.40 \\
\hline
\end{tabular}


Fig. 1 Schematic diagram of the laboratory apparatus developed for the miscible flow tests

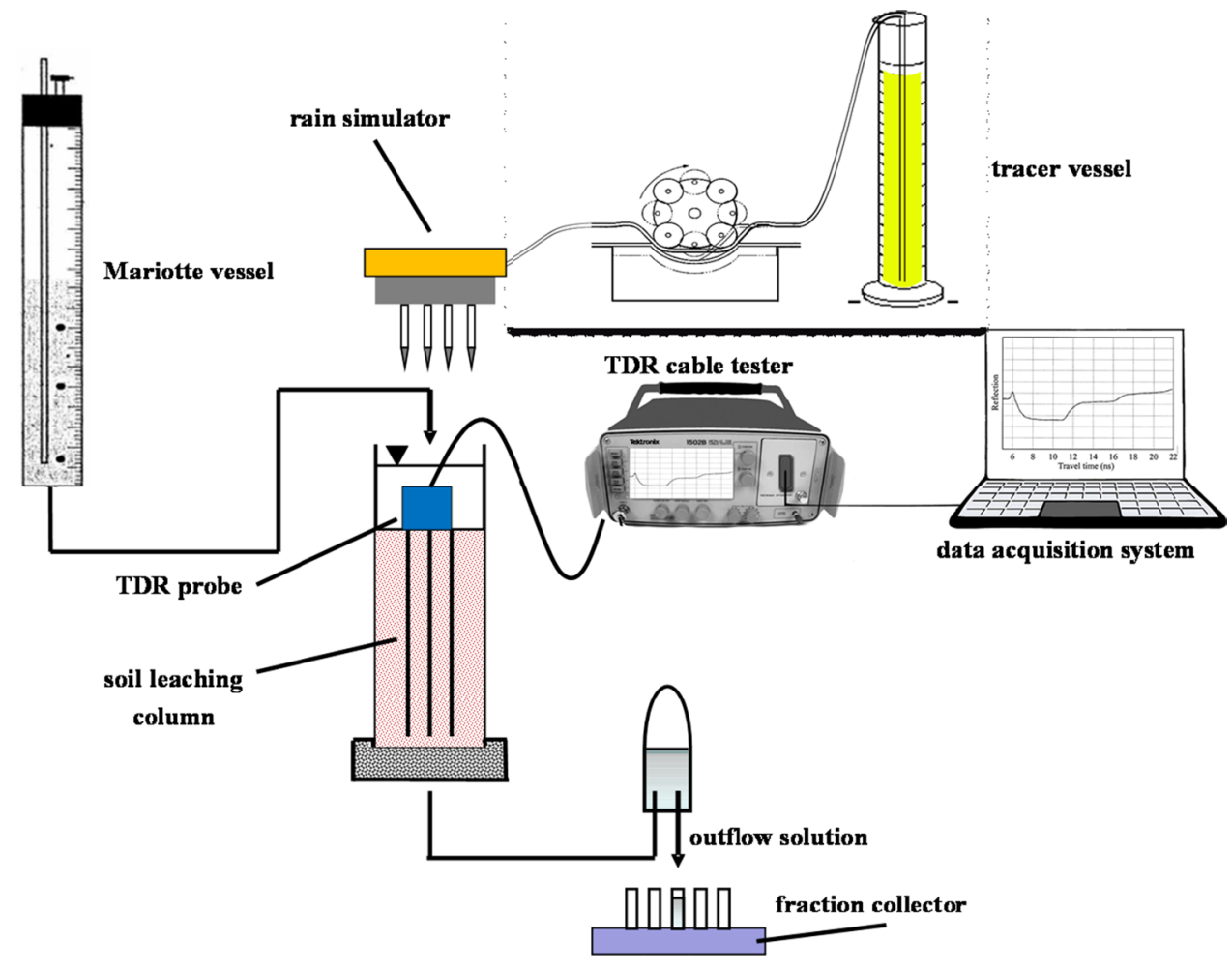

wave guides $10.5 \mathrm{~cm}$ long, iv) a computer for data acquisition and further analysis, v) a peristaltic pump connected to the rainfall simulator and vi) a fraction collector system.

For each sample, the experimental protocol $(\mathrm{P})$ involved three distinct one-dimensional leaching experiments, conducted under saturated, steady-state flow conditions. At the beginning of the primary test (PI), each soil core was saturated with water from the bottom to prevent air bubbles being trapped in soil pores. After vertically inserting a TDR probe, the soil column was fed with a $0.01 \mathrm{~N} \mathrm{CaSO}_{4}$ solution until a steady flow was reached. A Mariotte system allowed a constant ponding of $2 \mathrm{~cm}$ to be maintained on top of the soil column. At steady state, the input of water was interrupted and a volume of $20 \mathrm{~cm}^{3}$ of $\mathrm{KCl}$ solution (obtained by dissolving $45 \mathrm{~g}$ of potassium chloride in $1000 \mathrm{~cm}^{3}$ of water) was applied to the top of the sample. Once the solute pulse had completely penetrated across the top of the soil surface, it was shifted downward by supplying again the $0.01 \mathrm{~N}$ $\mathrm{CaSO}_{4}$ solution to the top of the soil through the Mariotte system, until all the solute had left the soil core.

At the end of test PI, a second experiment (PII) was conducted using the same procedure. Now, instead of $\mathrm{KCl}$, a volume of $20 \mathrm{~cm}^{3}$ of undiluted OMW (corresponding, according to the sample section area, to $50 \mathrm{~m}^{3} / \mathrm{ha}$ ) was supplied to the soil column and leached by $0.01 \mathrm{~N} \mathrm{CaSO}_{4}$ solution. Test PII was performed to simulate a real scenario whereby OMW disposal on soil was immediately followed by rainfall or an irrigation event. This scenario allowed us to determine the immediate effect of OMW on soil transport properties.

A conclusive leaching test (PIII) was performed by employing $\mathrm{KCl}$ once again as a tracer. In this last case, the soil sample treated with OMW was gradually saturated from the bottom with pure OMW and then incubated in a plastic box, at a controlled temperature of $25^{\circ} \mathrm{C}$, for 10 days to stimulate microbiological activities and extend the contact time between the soil and the wastewater, letting physical and chemical interactions effectively take place.

After these 10 days, the soil column was completely remediated by washing the $\mathrm{OMW}$ with $0.01 \mathrm{~N} \mathrm{CaSO}_{4}$ solution and a new transport test was carried out with the initial PI procedure. This test, unlike experiment PII, aimed to investigate the potential effects that OMW may produce on soils even for short residence times. This aspect is poorly investigated since most alterations to soil hydraulic and transport properties are expected to develop after multi-year OMW land applications.

Saturated hydraulic conductivity, $K_{s}$, was measured before each leaching test by adopting the constant head method (Klute and Dirksen 1986). During each leaching test, the electrical conductivity of the eluate, $E C_{w}$, was regularly monitored.

SWRCs were also determined on additional untreated (OMW-UTR) and treated (OMW-TR) soil samples, following the scheme in Fig. 2. Specifically, for each soil, OMW-UTR water retentions were determined on four samples (two undisturbed and two disturbed) by first saturating the soil with tap water and then drying it with 


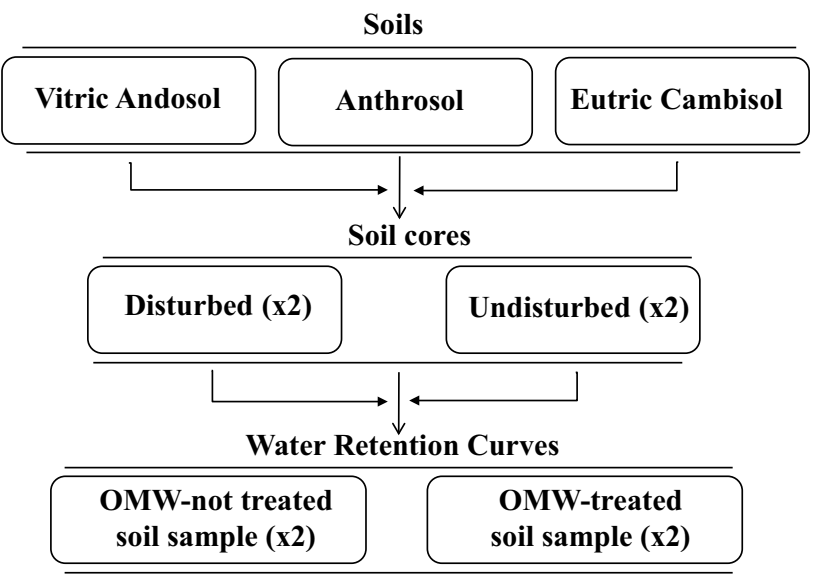

Fig. 2 Block diagram of the experimental protocol used for water retention curves estimates on OMW-treated and -untreated soil samples

a Stackman apparatus (Stackman et al. 1969). Drying was induced gradually by applying decreasing pressure heads in the range 0 to $-250 \mathrm{~cm}$ at the bottom of the soil cores. The same four soil samples, having been completely dried, were saturated with olive wastewater, and in accordance with the procedure described in the experiment (PIII), OMW was maintained inside the soil cores for 10 days. Soil samples (now OMW-TR) were then remediated from OMW (using a Mariotte apparatus similar to that described above), saturated with tap water and analysed again for water retention. For each soil, two replicates were considered (referred to below as \#1 and \#2), for both undisturbed and disturbed soil samples. Overall, twelve soil samples were analysed, obtaining 24 SWRCs.

Finally, the water retention experimental points were fitted using the water retention model of van Genuchten (1980):

$\theta=\theta_{r}+\frac{\theta_{s}-\theta_{r}}{\left[1+\alpha|\boldsymbol{h}|^{n}\right]^{m}}$

where $\theta\left(\mathrm{cm}^{3} / \mathrm{cm}^{3}\right)$ is the volumetric water content, $\theta_{r}\left(\mathrm{~cm}^{3} /\right.$ $\left.\mathrm{cm}^{3}\right)$ and $\theta_{s}\left(\mathrm{~cm}^{3} / \mathrm{cm}^{3}\right)$ are the residual volumetric water content and the water content at saturation, respectively, $h(\mathrm{~cm})$ is the pressure head, and $\alpha(1 / \mathrm{cm}), n(-)$ and $m(-)(m=1-1 / n)$ are the shape parameters. The RETC software package (van Genuchten et al. 1991) was used to implement the optimization algorithm procedure. All the measurements above were taken at a steady temperature of $25^{\circ} \mathrm{C}$.

\section{Results and discussion}

\section{Effects of OMW on soil transport properties}

The data collected from the transport experiments are illustrated in Fig. 3. For each soil and each scenario investigated (i.e. PI, PII and PIII), the figures show the experimental TDR-impedance BTCs.

Specifically, in Fig. 3 we observed that the progressive inflow of the solute applied at the soil surface gradually reduced the initial (background) impedance $Z_{i}$. A minimum value, $Z_{0}$, was reached when the entire solute mass entered the soil sample. This expected behaviour had already been observed in many previous experiments (Kachanoski et al. 1992; Mallants et al. 1996; Radcliffe et al. 1998; Comegna et al. 1999; Tilahun et al. 2004). As long as the solute mass was completely confined in the soil column, the measured impedances, $Z_{L}$, simply fluctuated around $Z_{0}$ since the TDR response is independent of solute location and only depends on the total mass "seen" in the probe observation volume (Kachanoski et al. 1992). Once the solute had started to leave the soil at the column bottom, $Z_{L}$ progressively increased and approached, during decontamination, its background value $Z_{i}$ once again.

For the whole set of leaching experiments, Table 3 reports the observed $Z_{i}$ and $Z_{0}$ impedances, and the time of solute application, $t_{0}$ (i.e. the time needed for the solute to completely enter the soil column), and the test duration, $t_{f}$ (i.e. the temporal duration of the leaching test).

Initial impedance $Z_{i}$ varied between $\approx 120 \Omega$ and $\approx 390$ $\Omega$. These differences may be mostly ascribed to the diverse pedological nature of the soils investigated (Mallants et al. 1994) and partly to the soil porosity (Jung et al. 2013). However, it is worth noting that, for a given soil, comparable $t_{0}$ and $t_{f}$ times were observed during tests PI and PII, whereas these times markedly increased during test PIII.

Going further into the analysis, it should be noted that tests PI and PII produce comparable BTCs, thus suggesting that when OMW application is followed by freshwater infiltration (for example rainfall or irrigation), the contaminant is rapidly mobilized and travels through the soil almost like $\mathrm{KCl}$ (i.e. as an inert non-adsorbing solute). This behaviour may have consequences on groundwater quality, which might be seriously compromised (for example by polyphenol mobility), especially in the presence of preferential flow pathways that are known to facilitate the downward movement of water and solutes (Coppola et al. 2009a, 2011, 2015a, b). By contrast, the result of PIII tests suggests that OMW persistence within the soil, even for a few days, plausibly promotes several physico-chemical and biological reactions that alter pre-existing flow mechanisms. This behaviour is quantitatively summarized in 

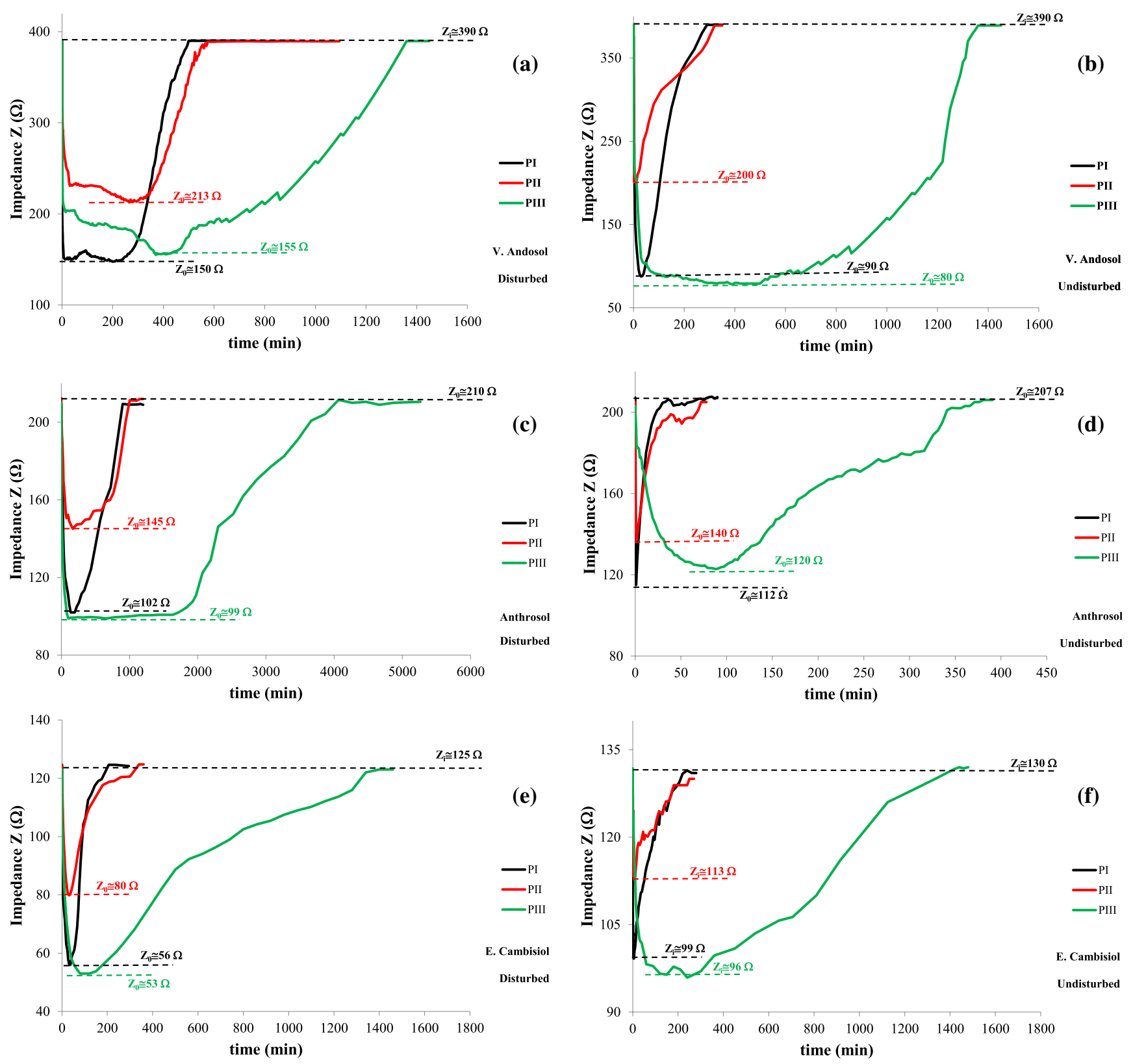

Fig. 3 Measured impedance $(Z)$ as a function of time: a Vitric Andosol (disturbed), b Vitric Andosol (undisturbed), c Anthrosol (disturbed), d Anthrosol (undisturbed), e Eutric Cambisol (disturbed), f Eutric Cambisol (undisturbed)

Table 3 Observed impedance values: $Z_{i}$ and $Z_{0}$, time of solute application $\left(t_{0}\right)$ and test duration $\left(t_{f}\right)$, with reference to the three soils investigated and PI, PII and PIII flow tests

\begin{tabular}{|c|c|c|c|c|c|c|c|c|c|c|c|c|c|}
\hline \multirow[t]{2}{*}{ Soil } & & \multicolumn{3}{|c|}{$Z_{i}(\Omega)$} & \multicolumn{3}{|c|}{$Z_{0}(\Omega)$} & \multicolumn{3}{|c|}{$\mathrm{t}_{0}(\min )$} & \multicolumn{3}{|c|}{$\mathrm{t}_{\mathrm{f}}(\min )$} \\
\hline & & PI & PII & PIII & PI & PII & PIII & PI & PII & PIII & PI & PII & PIII \\
\hline \multirow[t]{2}{*}{ V. Andosol } & dist ${ }^{*}$ & 390 & 390 & 390 & 150 & 213 & 155 & 28 & 27 & 49 & 905 & 1095 & 1460 \\
\hline & undist ${ }^{*}$ & 390 & 390 & 390 & 88 & 202 & 78 & 5 & 5 & 50 & 350 & 350 & 1450 \\
\hline \multirow[t]{2}{*}{ Anthrosol } & dist & 209 & 212 & 210 & 102 & 145 & 99 & 12 & 16 & 140 & 1200 & 1200 & 5265 \\
\hline & undist & 207 & 205 & 206 & 112 & 140 & 120 & $\approx 0.84$ & $\approx 0.70$ & 12 & 90 & 80 & 390 \\
\hline \multirow[t]{2}{*}{ E. Cambisol } & dist & 125 & 124 & 123 & 56 & 80 & 53 & 4.1 & 5 & 25 & 295 & 360 & 1460 \\
\hline & undist & 131 & 131 & 132 & 99 & 113 & 96 & 2 & 2.5 & 15 & 280 & 270 & 1480 \\
\hline
\end{tabular}

*disturbed: dist.; undisturbed: undist. (soil samples) 


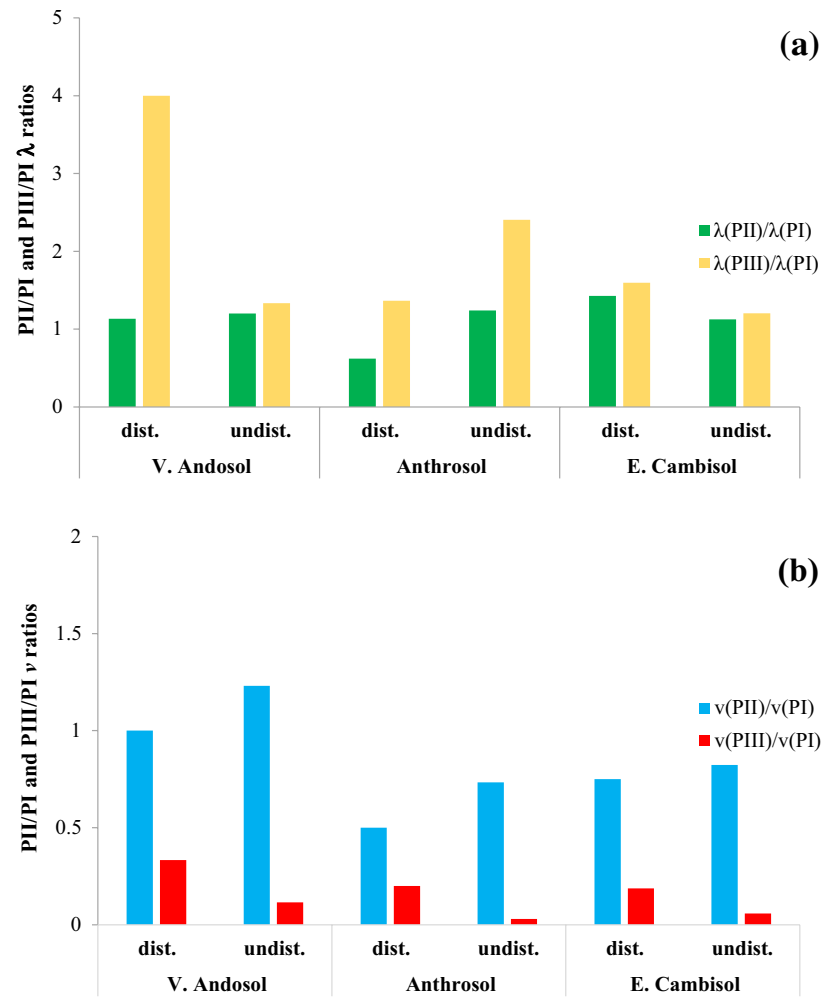

Fig. 4 Effects of OMW on solute transport parameters: a) dispersivity $\lambda$, and b) pore water velocity $v$, determined as the ratio of corresponding $\lambda$ and $v$ values calculated among PI, PII and PIII experiments

Fig. 4, which reports the ratios between the corresponding values of average pore water velocity, $v$, and dispersivity, $\lambda$, estimated among tests PI, PII and PIII.

Further information is presented in Table 4, showing the estimated solute arrival time, $t_{\text {peak }}$ (i.e. the time corresponding to the arrival of the solute peak at the observation section $L=11 \mathrm{~cm}$ ) and the peak solute velocity, $v_{\text {peak }}=L / t_{\text {peak }}$. The most obvious outcome of Fig. 4 is the severe reduction of $v$ and the enhancement of the dispersivity $\lambda$ after OMW treatment (treatment PIII), whereas data from Table 4 reveal the higher times that a solute peak requires to propagate within the soil.

To conclude the examination of the dataset, the second Pearson's coefficient of skewness, $\alpha_{2}$, was also calculated for each transport experiment. This coefficient provides further insights into OMW changes of soil transport properties, albeit qualitative (Table 5). We focused on the $\alpha_{2}$ changes before and after OMW soil treatment. Specifically, we verified that the $\alpha_{2}$ values are in all cases greater than zero and range between 0.5 and 1.4. In general, $\alpha_{2}$ values higher than unity were observed in undisturbed soil columns. These values denote asymmetrical (positively skewed) curves that are plausibly attributable to some form of a non-equilibrium transport mechanism that usually occurs in structured soils with large pores between aggregates (Mallants et al. 1994; Vanderborght et al. 1997; Coppola et al. 2009a, b). Disturbed soils exhibited $\alpha_{2}$ values that are consistent with slightly asymmetric bell-shaped curves, which are generally observed in the case of non-adsorbed solutes moving in homogeneous (repacked) soils (Wierenga and van Genuchten 1989; Vanclooster et al. 1993; Comegna et al. 2001; Coppola et al. 2009a among others).

In all cases, $\alpha_{2}$ values decreased after OMW treatment. This reduction was more pronounced for undisturbed than for repacked soils. In repacked soils, which have a negligible soil structure, OMW treatments may induce minor changes in the initial pore system.

The findings discussed above in this section, albeit from experimental observations obtained at limited time scales, are consistent with the research of Mahmoud et al. (2010) and Mohawesh et al. (2014) who studied the OMW

Table 5 Second Pearson's coefficient of skewness $\left(\alpha_{2}\right)$ estimates for the laboratory $\mathrm{EC}_{\mathrm{w}}$ vs time measurements of experiments PI, PII and PIII

\begin{tabular}{lllll}
\hline Soil & & \multicolumn{2}{l}{$\begin{array}{l}\text { Second Pearson's coefficient } \\
\text { of skewness }\left(\alpha_{2}\right)\end{array}$} \\
\cline { 3 - 5 } & & PI & PII & PIII \\
\hline V. Andosol & dist & 0.7 & 0.8 & 0.6 \\
& undist & 1.1 & 1.2 & 0.7 \\
Anthrosol & dist & 0.8 & 0.7 & 0.5 \\
& undist & 1.2 & 1.3 & 0.7 \\
E. Cambisol & dist & 0.8 & 0.7 & 0.6 \\
& undist & 1.4 & 1.3 & 1.0 \\
\hline
\end{tabular}

Table 4 Solute arrival time $t_{\text {peak }}$ (min) and peak solute velocity $v_{\text {peak }}(\mathrm{cm} / \mathrm{min})$, estimated on the $\mathrm{EC}_{\mathrm{w}}$ vs time curves of experiments PI, PII and PIII

\begin{tabular}{|c|c|c|c|c|c|c|c|}
\hline \multirow[t]{2}{*}{ Soil } & & \multicolumn{2}{|c|}{ Experiment PI } & \multicolumn{2}{|c|}{ Experiment PII } & \multicolumn{2}{|c|}{ Experiment PIII } \\
\hline & & $\mathrm{t}_{\text {peak }}$ & $v_{\text {peak }}$ & $\mathrm{t}_{\text {peak }}$ & $v_{\text {peak }}$ & $t_{\text {peak }}$ & $v_{\text {peak }}$ \\
\hline \multirow[t]{2}{*}{ V. Andosol } & dist & 425 & 0.03 & 524 & 0.03 & 714 & 0.02 \\
\hline & undist & 43 & 0.30 & 33 & 0.39 & 580 & 0.02 \\
\hline \multirow[t]{2}{*}{ Anthrosol } & dist & 137 & 0.04 & 285 & 0.04 & 1917 & 0.006 \\
\hline & undist & 11 & 1.07 & 11 & 1.07 & 148 & 0.08 \\
\hline \multirow[t]{2}{*}{ E. Cambisol } & dist & 61 & 0.18 & 63 & 0.17 & 417 & 0.03 \\
\hline & undist & 16 & 0.41 & 26 & 0.41 & 117 & 0.09 \\
\hline
\end{tabular}


long-term effects on soils. The above authors demonstrated that multi-year OMW application caused a reorganization of the natural soil porosity with the reduction in larger pores and the complementary increase in finer pores. This modification may well be ascribed to the presence in OMW of grease and oil, organic matter, suspended and soluble salts. Organic matter and salts contribute to cement and reaggregate soil particles, blocking macropores partially or completely. Fats are retained in soil pores of any diameter, thereby reducing their size. Pore size may also be reduced by the clay dispersion phenomenon, which is another recognized negative effect of OMWs (Moraetis et al. 2011; Barbera et al. 2013).

\section{Effects of OMW on soil hydraulic properties}

For the sake of completeness, we recall in Fig. 5 the $K_{s}$ values determined at the beginning of each leaching test. In particular, the graph in Fig. 5, similarly to that in Fig. 4, aims to interpret the changes in the $K_{s}$ values, due to OMW, through the ratios of the conductivity values obtained from tests PI, PII and PIII. Consistent with the results discussed in Sect. 3.1, $K_{s}$ decreased after OMW treatment (up to $90 \%$ ), whereas their values remained almost stable between PI and PII.

The SWRCs, for all the soils and treatments considered, are shown in Fig. 6. For a given soil, distinct curves were obtained for repacked and non-repacked soils, as well as for OMW-untreated and OMW-treated soil samples. It is worth noting that the SWRCs determined on repacked soils (Fig. 6a, c and e,) were only slightly or not at all influenced by OMW treatment, as the SWRCs obtained on OMWuntreated and -treated samples in practice overlapped. By contrast, as emerges from Fig. 6b, 6d and f, OMW treatment

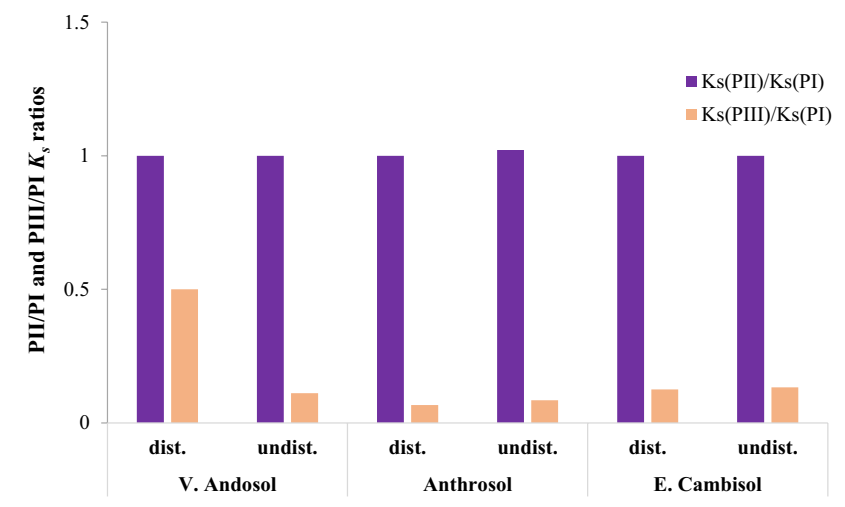

Fig. 5 Effects of OMW on soil hydraulic conductivity at saturation, $K_{s}$, determined as the ratio between the estimated $K_{s}$ values among PI, PII and PIII experiments increased the water retention of undisturbed soil cores. These results, which are consistent with the outcome of the leaching experiments, are comparable with those of Mohawesh et al. (2014).

The van Genuchten model parameters, $\alpha$ and $n$, estimated for all the SWRCs, as well as the ratios $\alpha_{\mathrm{TR}} / \alpha_{\mathrm{UTR}}$ and $\mathrm{n}_{\mathrm{TR}} /$ $\mathrm{n}_{\text {UTR }}$ between treated (TR) and untreated (UTR) soil samples, are reported in Table 6. Each parameter is obtained as the mean of the values obtained from the two replicates (i.e. mean of sample \#1, and sample \#2). The parameters clearly confirm the behaviour observable in the curves. For the undisturbed soils, OMW treatment reduces both parameters $\alpha$ and $\mathrm{n}$. Smaller values of $\alpha$ suggest a narrowing of the larger pores. Given that the water retention of the disturbed soils was only slightly modified by the treatment, the decrease in $\alpha$ may well be ascribed to a loss of the internal structure of the soil. Instead, a smaller $n$ indicates a growth of water retention. The ratios between values $\alpha$ and $n$ obtained for treated and untreated soil samples (Table 6) again clearly illustrate that the soil porous systems of the undisturbed soil samples were more impacted by OMW treatment than the soil porous systems of the disturbed soil samples. All these results are consistent with the reduction in both hydraulic conductivity and average $v$ values discussed above.

\section{Conclusions}

The TDR technique, though already used in the field of soil hydrology to measure soil volumetric water content and to estimate chemical transport parameters in natural soils, was successfully used in the present research to confirm the impact of OMW in soil structural alterations, which is nowadays the subject of much debate worldwide.

In particular, we studied the effects of OMW disposal on the hydraulic and transport properties of three selected soils in southern Italy. Different leaching experiments, conducted at laboratory scale, were performed using $\mathrm{KCl}$ and $\mathrm{OMW}$. Measurements of impedance $Z_{L}$ (within each soil sample) were taken during these laboratory tests to define the experimental BTCs.

The experiments performed under different conditions showed that soils exhibited a marked alteration of the observed properties after OMW treatment. In particular, our results proved that the effects of OMW on the soil porous system should be less pronounced in disturbed soils than in well-consolidated soils, and that the effect of OMW on soil hydraulic and transport properties is not immediate (it is observed but not so pronounced). Although many have 

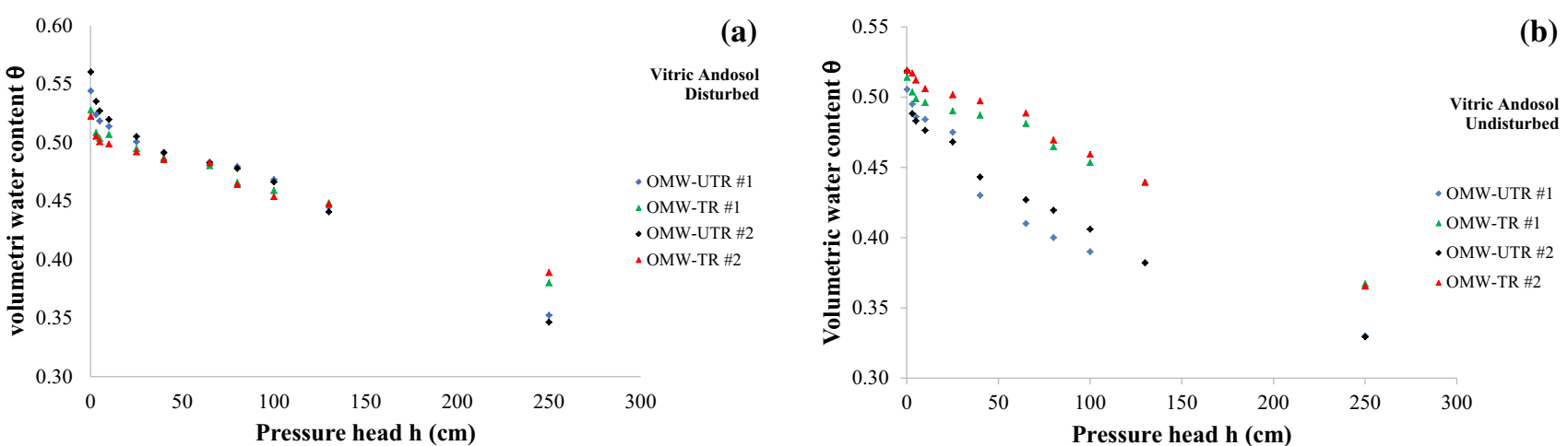

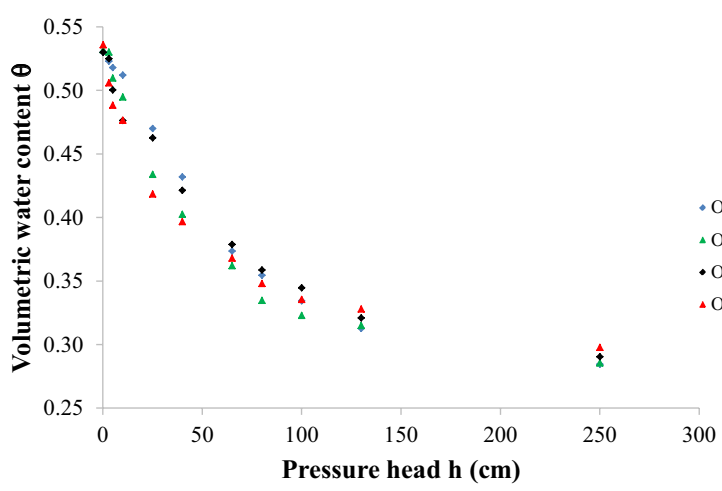

(c)

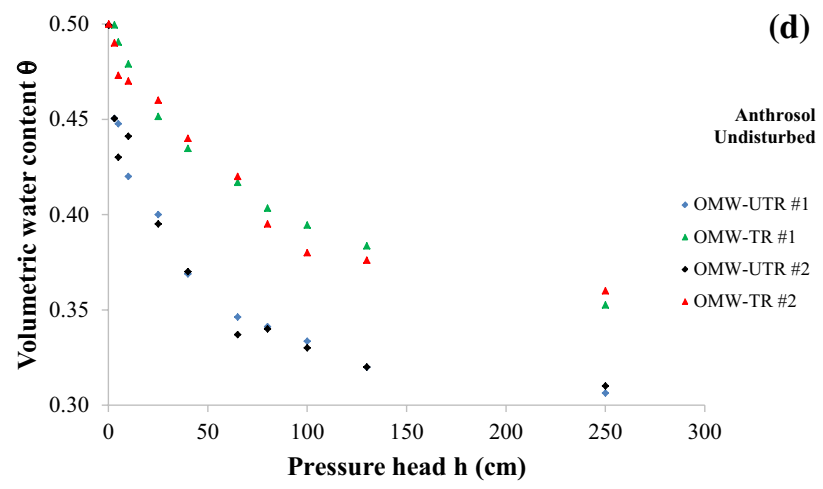

(e)

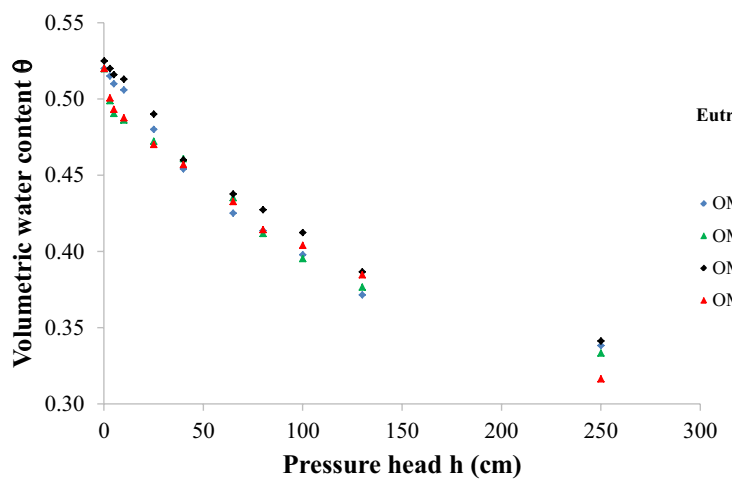

Fig. 6 Experimental SWRCs calculated before (OMW-UTR) and after (OMW-TR) OMW treatment: a Vitric Andosol (disturbed), sample \#1 and sample \#2, b Vitric Andosol (undisturbed) sample \#1 and sample \#2, c Anthrosol (disturbed) sample \#1 and sample \#2, d

focused elsewhere on long-term OMW effects on soils, our study showed that these changes can be relatively swift since we noted important alterations in the soils in question already after 10 days of OMW incubation. This aspect, as discussed above, is in general underestimated and requires further clarification.

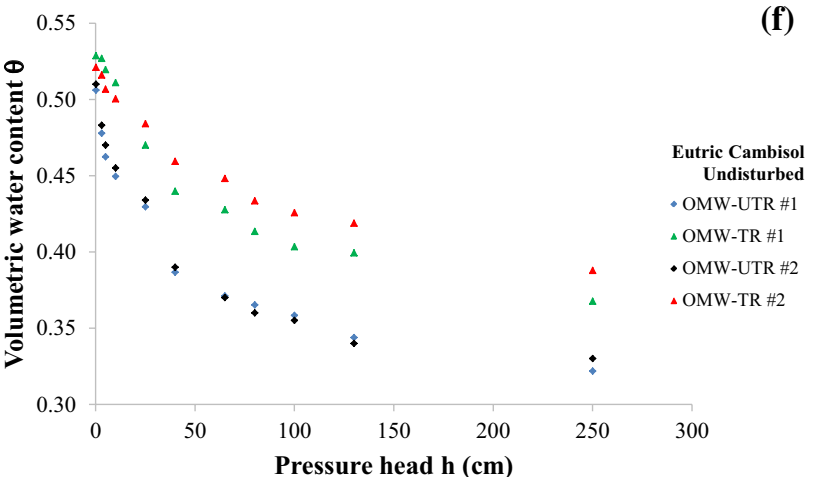

Anthrosol (undisturbed) sample \#1 and sample \#2, e Eutric Cambisol (disturbed) sample \#1 and sample \#2, f) Eutric Cambisol (undisturbed) sample \#1 and sample \#2

Soil hydraulic and transport changes may always be related to significant deviations of the original pore size distribution of soils that reassemble their internal structure. It is well documented that the expected presence in OMW of organic matter, salts, oil and grease may have different 
Table 6 Van Genuchten's model parameters $\alpha, \mathrm{n}$, of soil water retention, and coefficient of determination $\mathrm{r}^{2}$ obtained, for each soil, as the arithmetic mean from the two soil replicates and the calculated ratios $\alpha_{\mathrm{TR}} / \alpha_{\mathrm{UTR}}$ and $\mathrm{n}_{\mathrm{TR}} /$ $\mathrm{n}_{\mathrm{UTR}}$, between treated (TR) and untreated (UTR) soil samples

\begin{tabular}{|c|c|c|c|c|c|c|c|}
\hline Soil & & SWRC ID & $\alpha$ & $\mathrm{n}$ & $r^{2}$ & $\alpha_{\mathrm{TR}} / \alpha_{\mathrm{UTR}}$ & $\mathrm{n}_{\mathrm{TR}} / \mathrm{n}_{\mathrm{UTR}}$ \\
\hline \multirow[t]{4}{*}{ V. Andosol } & \multirow[t]{2}{*}{ disturbed } & OMW-UTR & 0.006 & 1.571 & 0.95 & \multirow[t]{2}{*}{1.0} & \multirow[t]{2}{*}{0.95} \\
\hline & & OMW-TR & 0.006 & 1.491 & 0.96 & & \\
\hline & \multirow[t]{2}{*}{ undisturbed } & OMW-UTR & 0.022 & 1.228 & 0.97 & \multirow[t]{2}{*}{0.76} & \multirow[t]{2}{*}{1.28} \\
\hline & & OMW-TR & 0.005 & 1.576 & 0.99 & & \\
\hline \multirow[t]{4}{*}{ Anthrosol } & \multirow[t]{2}{*}{ disturbed } & OMW-UTR & 0.045 & 1.279 & 0.96 & \multirow[t]{2}{*}{0.23} & \multirow[t]{2}{*}{0.82} \\
\hline & & OMW-TR & 0.034 & 1.212 & 1.00 & & \\
\hline & \multirow[t]{2}{*}{ undisturbed } & OMW-UTR & 0.392 & 1.108 & 0.97 & \multirow[t]{2}{*}{0.33} & \multirow[t]{2}{*}{0.812} \\
\hline & & OMW-TR & 0.130 & 1.105 & 0.99 & & \\
\hline \multirow[t]{4}{*}{ E. Cambisol } & \multirow[t]{2}{*}{ disturbed } & OMW-UTR & 0.042 & 1.209 & 0.98 & \multirow[t]{2}{*}{0.67} & \multirow[t]{2}{*}{0.95} \\
\hline & & OMW-TR & 0.028 & 1.273 & 0.97 & & \\
\hline & \multirow[t]{2}{*}{ undisturbed } & OMW-UTR & 0.134 & 1.212 & 0.98 & \multirow[t]{2}{*}{0.63} & \multirow[t]{2}{*}{0.92} \\
\hline & & OMW-TR & 0.084 & 1.115 & 0.99 & & \\
\hline
\end{tabular}

contrasting effects on soils. In our research, we observed a modification of the soil porosity distribution and soil aggregates, with an overall increase in micropores combined with macropore loss. The final result was a more anastomosed network of narrow pathways that limited the transfer of water and solutes within soils.

Based on our evidence, application of OMW on soils should in general be avoided to prevent such mechanisms that: i) reduce solute diffusion into soil aggregates, with the possible consequence of an increase in dissolved substances that persist within the soil matrix, and ii) favour the formation of films on the surface of aggregates, which enhances soil hydrophobicity. Finally, the increase in micropores could play, as is well known, a negative role in root growth, with possible consequences on crop production.

Acknowledgements The authors wish to thank all who assisted in conducting this work.

Funding Open access funding provided by Università degli Studi della Basilicata within the CRUI-CARE Agreement.

\section{Declarations}

Conflict of interest The authors declare that they have no conflict of interest.

Open Access This article is licensed under a Creative Commons Attribution 4.0 International License, which permits use, sharing, adaptation, distribution and reproduction in any medium or format, as long as you give appropriate credit to the original author(s) and the source, provide a link to the Creative Commons licence, and indicate if changes were made. The images or other third party material in this article are included in the article's Creative Commons licence, unless indicated otherwise in a credit line to the material. If material is not included in the article's Creative Commons licence and your intended use is not permitted by statutory regulation or exceeds the permitted use, you will need to obtain permission directly from the copyright holder. To view a copy of this licence, visit http://creativecommons.org/licenses/by/4.0/.

\section{References}

Albalasmeh AA, Alajlouni MA, Ghariabeh MA, Rusan MJ (2019) Short-term effects of olive mill wastewater land spreading on soil physical and hydraulic properties. Water Air Soil Pollut 230:208. https://doi.org/10.1007/s11270-019-4243-5

Allison LE (1965) Organic carbon, in A. Klute (Ed.). Methods of Soil Analysis, Part 1, Madison, Agron. Monograph, vol. 9, ASA and SSSA, 1367-1378

Andreozzi R, Canterino M, Di Somma I, Lo Giudice R, Marotta R, Pinto G, Pollio A (2007) Effect of combined physico-chemical processes on the phytotoxicity of olive mill wastewaters. Water Res 42:1684-1692

Barbera AC, Maucieri C, Cavallaro V, Ioppolo A, Spagna G (2013) Effects of spreading olive mill wastewater on soil properties and crops, a review. Agr Water Manage 119:43-53

Belaqziz M, Lakhal E, Mbouobda H, El Hadrami I (2008) Land spreading of olive mill wastewater: effect on maize (Zea maize) crop. J Agron 7:297-305

Belaqziz M, Abbassi A, Lakhal E, Agrafioti E, Galanakis SM (2016) Agronomic application of olive mill wastewater: Effects on maize production and soil properties. J Environ Manage 171:158-165. https://doi.org/10.1016/j.jenvman.2016.02.006

Blake GR, Hartge KH (1986) Particle density. In: Klute A (ed) Methods of Soil Analysis, Part 1, 2nd edn. American Society of Agronomy, Madison, WI, pp 377-381

Box JD (1983) Investigation of the Folin-Ciocalteu phenol reagent for the determination of the polyphenolic substances in natural waters. Water Res 17:249-261 
Butters GL, Jury WA (1989) Field scale transport of bromide in an unsaturated soil, 2 Dispersion Modelling. Water Resour Res 25:1583-1589

Caputo MC, De Girolamo AM, Volpe A (2013) Soil amendment with olive mill wastes: impact on groundwater. J Environ Manage 131:216-221

Chatzistathis T, Koutsos T (2017) Olive mill wastewater as a source of organic matter, water and nutrients for restoration of degraded soils and for crops managed with sustainable systems. Agric Water Manag 190(2017):55-64. https://doi.org/10.1016/j.agwat. 2017.05.008

Chehaba H, Tekayab M, Ouhibic M, Gouiaad M, Zakhamae H, Mahjouba Z, Laamaria S, Sfinaa H, Chihaouia B, Boujnaha D, Mechrib B (2019) Effects of compost, olive mill wastewater and legume cover cropson soil characteristics, tree performance and oil quality of olive trees cv. Chemlali grown under organic farming system. Sci Hortic 253:163-171. https://doi.org/10.1016/j. scienta.2019.04.039

Comegna V, Coppola A, Sommella A (1999) Nonreactive solute transport in variously structured soil materials as determined by laboratory-based time domain reflectometry (TDR). Geoderma 92:167-184

Comegna V, Coppola A, Sommella A (2001) Effectiveness of equilibrium and physical non-equilibrium approaches for interpreting solute transport through undisturbed soil columns. J Contam Hydrol 50:121-138. https://doi.org/10.1016/S0169-7722(01) 00100-0

Comegna A, Coppola A, Dragonetti G, Sommella A (2013a) Dielectric response of a variable saturated soil contaminated by Non-Aqueous Phase Liquids (NAPLs). Procedia Environ Sci 19:701-710

Comegna A, Coppola A, Dragonetti G, Chaali N, Sommella A (2013b) Time domain reflectometry-measuring dielectric permittivity to detect soil non-aqueous phase liquids contamination-decontamination processes. J Agric Eng, XLIV(s1), e167

Comegna A, Coppola A, Dragonetti G, Severino G, Sommella A, Basile A (2013c) Dielectric properties of a tilled sandy volcanicvesuvian soil with moderate andic features. Soil till Res 133:93100. https://doi.org/10.1016/j.still.2013.06.003

Comegna A, Coppola A, Dragonetti G, Sommella A (2016) Estimating non-aqueous phase liquid (NAPL) content in variable saturated soils using time domain reflectometry (TDR). Vadose Zone J. https://doi.org/10.2136/vzj2015.11.0145

Comegna A, Coppola A, Dragonetti G, Sommella A (2017) Interpreting TDR signal propagation through soils with distinct layers of nonaqueous-phase liquid and water content. Vadose Zone J. https://doi.org/10.2136/vzj2017.07.0141

Comegna A, Coppola A, Dragonetti G (2019) A soil non-aqueous phase liquid (NAPL) flushing laboratory experiment based on measuring the dielectric properties of soil-organic mixtures via time domain reflectometry (TDR). Hydrol Earth Syst Sci 23:3593-3602. https://doi.org/10.5194/hess-23-3593-2019

Comegna A, Coppola A, Dragonetti G (2020) Time domain reflectometry for dielectric characterization of olive mill wastewater contaminated soils. J Agr Eng 1092:248-254. https://doi.org/10. 4081/jae.2020.1092
Coppola A, Comegna V, Basile A, Lamaddalena N, Severino G (2009a) Darcian preferential water flow and solute transport through bimodal porous systems: experiments and modelling. J Hydrol Contam. https://doi.org/10.1016/j.jconhyd.2008.10.004

Coppola A, Kutilek M, Frind EO (2009b) Transport in preferential flow domains of the soil porous system: measurement, interpretation, modelling, and upscaling. J Hydrol Contam. https://doi.org/10. 1016/j.jconhyd.2008.05.011

Coppola A, Comegna A, Dragonetti G, Dyck M, Basile A, Lamaddalena N, Comegna V (2011) Solute transport scales in an unsaturated stony soil. Adv Water Resour 34(6):747-759

Coppola A, Comegna A, Dragonetti G, Gerke HH, Basile A (2015a) Simulated Preferential Water Flow and Solute Transport in Shrinking Soils. Vadose Zone J. https://doi.org/10.2136/vzj20 15.02.0021

Coppola A, Chaali N, Dragonetti G, Lamaddalena N, Comegna A (2015b) Root uptake under non-uniform root-zone salinity. Ecohydrology, 1363-1379, ISSN: 1936-0584. https://doi.org/10. 1002/eco.1594

Cox L, Celis R, Hermosin MC, Becker A, Cornejo J (1997) Porosity and herbicide leaching in soils amended with olive mill wastewater. Agr Ecosyst Environ 65:151-161

Dalton FN, Herkelrath WN, Rawlins DS, Rhoades JD (1984) Timedomain reflectometry: simultaneous measurement of soil water content and electrical conductivity with a single probe. Science 224:989-990

Day PR (1965) Particle fractionation and particle-size analysis. In: Black CA (ed) Methods of Soil Analysis, Part 1. American Society of Agronomy, Madison, pp 545-567

Dragonetti G, Comegna A, Ajeel A, Deidda G, Lamaddalena N, Rodriguez G, Vignoli G, Coppola A (2018) Calibrating electromagnetic induction conductivities with time-domain reflectometry measurements. Hydrol Earth Syst Sci 22:1509-1523. https://doi.org/10. 5194/hess-22-1509-2018

Eckert DJ (1988) Soil pH, in W.C. Dahnke (Ed.), Recommended chemical soil test procedures for the North Central Region. Fargo: North Dakota Agricultural Experiment Station Bulletin No. 221 (revised), 6-8

Elrick DE, Kachanoski RG, Pringle EA, Ward A (1992) Parameter estimation on field solute transport models based on time domain reflectometry measurements. Soil Sci Soc Am J 56:1663-1666

Francisca M, Montoro MA (2012) Measuring the dielectric properties of soil-organic mixtures using coaxial impedance dielectric reflectometry. J Appl Geophys 80:101-109

Gharaibeh MA, Eltaif NI, Al-Abdullah B (2007) Impact of field application of treated wastewater on hydraulic properties of vertisols. Water Air Soil Pollut 184:347-353

Helrich K (1990) Official methods of analysis of the association of official analytical chemists, 15 th edn. Association of Official Analytical Chemists Inc., Arlington, p 807

IRSA-CNR (2003) Metodi analitici per le acque. APAT, Rapporti, 29, ISBN 88-448-0083-7

IUSS Working Group WRB (2006) World reference base for soil resources 2006. A framework for international classification, 
correlation and communication. 2nd edn. World Soil Resour. Rep. 103. FAO, Rome

Jarvis N, Etana A, Stagnitti F (2008) Water repellency, near-saturated infiltration and preferential solute transport in a macroporous clay soil. Geoderma 143:223-230

Jirků V, Kodešová R, Nikodem A, Mühlhanselová M, Žigová A (2013) Temporal variability of structure and hydraulic properties of topsoil of three soil types. Geoderma 204-205:43-58

Jung S, Drnevich VP, Abou Najm MR (2013) New methodology for density and water content by time domain reflectometry. $\mathrm{J}$ Geotech Geoenviron Eng 139:659-670. https://doi.org/10.1061/ (ASCE)GT.1943-5606.0000783

Jury A, Roth K (1990) Transfer functions and solute movement through soil. Birkhäuser Verlag, $226 \mathrm{pp}$

Kachanoski RG, Pringle E, Ward A (1992) Field measurement of solute travel time using time domain reflectometry. Soil Sci Soc Am J 56:47-52

Kavvadias V, Doula M, Theocharopoulos S (2014) Long-term effect on soil of the disposal of olive mill waste waters (OMW). Environmental Forensic 15:37-51

Klute A, Dirksen C (1986) Hydraulic Conductivity and Diffusivity: Laboratory Methods. In: A. Klute (Eds.). Methods of Soil Analysis. Part 1. Physical and Mineralogical Methods. SSA Book Series: 5

Levy GJ, Dag A, Raviv M, Zipori I, Medina S, Saadi I, Krasnovski A, Eizenberg H, Laor Y (2018) Annual spreading of olive mill wastewater over consecutive years: effects on cultivated soils' physical properties. Land Degrad Dev 29:176-187

Lopez-Pinieiro A, Fernandez J, Albarran A, Rato Nunes JM, Barreto C (2008) Effects of de-oiled two-phase olive mill waste on Mediterranean soils and the wheat crop. Soil Sci Soc Am J 72:424-430

Magdich S, Abid W, Boukhris M, Ben Rouina B, Ammar A (2016) Effects of long-term olive mill wastewater spreading on the physiological and biochemical responses of Chemlali olive trees (Olea europaea L.). Ecol Eng 97:122-129

Mahmoud M, Janssen M, Haboub N, Nassour A, Lennartz B (2010) The impact of olive mill wastewater application on flow and transport properties in soils. Soil and till Res 107:36-41

Mahmoud M, Janssen M, Peth S, Horn R, Lennartz B (2012) Long term impact of irrigation with olive mill wastewater on aggregate properties in the top soil. Soil and Tillage Research 124:24-31

Mallants D, Vanclooster M, Meddahi M, Feyen J (1994) Estimating solute transport in undisturbed soil columns using time-domain reflectometry. J Contam Hydrol 17:91-109

Mallants D, Vanclooster M, Toride N, Vanderborght J, van Genuchten MTh, Feyen J (1996) Comparison of three methods to calibrate $\mathrm{tdr}$ for monitoring solute movement in undisturbed soil. Soil Sci Soc Am J 60:747-754

Meftah O, Guergueba Z, Brahama M, Sayadib S, Mekkia A (2019) Long term effects of olive mill wastewaters application on soil properties and phenolic compounds migration under arid climate.
Agric Water Manag 212:119-125. https://doi.org/10.1016/j.agwat. 2018.07.029

Mekki A, Aloui A, Guergueb Z, Braham M (2018) Agronomic valorization of olive mill wastewaters: effects on medicago sativa growth and soil characteristics. Clean: Soil, Air, Water. https:// doi.org/10.1002/clen.201800100

Mohawesh O, Mohmoud M, Jansen M, Lemartz B (2014) Effect of irrigation with olive mill wastewater on soil hydraulic and solute transport. Int J Environ Sci Technol 3:1-10

Moraetis D, Stamati FE, Nikolaidis NP, Kalogerakis N (2011) Olive mill wastewater irrigation of maize: Impacts on soil and groundwater. Agr Water Manage 98:1125-1132

Nadler AS, Dasberg S, Lapid I (1991) Time domain reflectometry measurements of water content and electrical conductivity of layered soil columns. Soil Sci Soc Am J 55:938-943

Nikodem A, Kodešová R, Fér M, Klement K (2021) Using scaling factors for characterizing spatial and temporal variability of soil hydraulic properties of topsoils in areas heavily affected by soil erosion. J Hydrology 593:125897

Pedrero F, Grattan SR, Ben-Gal A, Vivaldi GA (2020) Opportunities for expanding the use of wastewaters for irrigation of olives. Agricultural Water Manage 241:106333

Persson M, Berndtsson R (2002) Measuring nonaqueous phase liquid saturation in soil using time domain reflectometry. Water Resour Res. https://doi.org/10.1029/2001WR000523

Piotrowska A, Rao MA, Scotti R, Gianfreda L (2011) Changes in soil chemical and biochemical properties following amendment with crude and dephenolized olive mill waste water (OMW). Geoderma 161:8-17

Radcliffe DE, Gupta SM, Box JE (1998) Solute transport at the pedon and polypedon scales. Nutr Cycl Agroecosyst 50:77-84

Regni L, Nasini L, Ilarioni L, Brunori A, Massaccesi L, Agnelli A, Proietti P (2017) Long term amendment with fresh and composted solid olive mill waste on olive grove affects carbon sequestration by prunings, fruits, and soil. Front Plant Sci 7:2042. https://doi. org/10.3389/fpls.2016.02042

Rhoades JD, Raats PAC, Prather RJ (1976) Effects of liquid-phase electrical conductivity, water content, and surface conductivity on bulk soil electrical conductivity. Soil Sci Soc Am J 5:651-655

Rhoades JD, Manteghi NA, Shouse PJ, Alves WJ (1989) Soil electrical conductivity and soil salinity: new formulations and calibrations. Soil Sci Soc Am J 53:433-439

Roig A, Cayuela ML, Sanchez-Monedero MA (2006) An overview on olive mill wastes and their valorisation methods. Waste Manage 26:960-969

Saadi I, Laor Y, Raviv M, Medina S (2007) Land spreading of olive mill wastewater: effects on soil microbial activity and potential phytotoxicity. Chemosphere 66:75-83

Sahraoui H, Kanzari S, Hachicha M, Mellouli HJ (2015) Olive mill wastewater spreading effects on hydraulic soil properties. The Experiment 30:2002-2011 
Severino G, Comegna A, Coppola A, Sommella A, Santini A (2010) Stochastic analysis of a field-scale unsaturated transport experiment. Adv Water Resour 33:1188-1198. https://doi.org/10.1016/j. advwatres.2010.09.004

Stackman WP, Valk GA, van der Harst GG (1969) Determination of soil moisture retention curves: I. Sand box apparatus, in: Range (Ed.). Wageningen, ICW, pp. 119

Steinmetz Z, Kurtz MP, Dag A, Zipori I, Schaumann GE (2015) The seasonal influence of olive mill wastewater applications on an orchard soil under semi-arid conditions. J Plant Nutr Soil Sci 178:641-648

Tilahun K, Botha JF, Bennie ATP (2004) Comparison of bromide and nitrate transport in the Bainsvlei soil of South Africa under natural rainfall. Water 30:9-16

Topp GC, Davis JL, Annan AP (1980) Electromagnetic determination of soil water content: measurement in coaxial transmission lines. Water Resour Res 16:574-582
Umeugochukwo O (2016) Mitigation of soil degradation, and ground water pollution caused by on-land disposal of vegetable oil mill effluents. Thesis, University of Stellenbosch, South Africa, PdD

van Genuchten MTh (1980) A closed-form equation for predicting the hydraulic conductivity of unsaturated soils. Soil Sci Soc Am J 44:892-898

van Genuchten MTh, Leij FT, Yates SR (1991) The RETC code for quantifying the hydraulic functions of unsaturated soils, Rep. EPA/600/2-91/065, U.S. Environ. Protect. Agency, Ada, Okla

Vanclooster M, Mallants D, Diels J, Feyen J (1993) Determining localscale solute transport parameters using time domain reflectometry (TDR). J Hydrol 148:93-107

Vanderborght J, Gonzalez C, Vanclooster M, Mallants D, Feyen J (1997) Effects of soil type and water flux on solute transport. Soil Sci Soc Am J 61:372-389

Wierenga PJ, van Genuchten MTh (1989) Solute transport through small and large unsaturated soil columns. Ground Water 27:35-42 